\title{
Characterization of the Molecular Orientation in LB Films of Rhodamine B Derivatives by the Optical Second Harmonic Generation Coherent Interferometry
}

\author{
Ryo BABA*, Ken-ichi ISHIBASHI, Osamu SATO, Kazuhito HASHIMOTO \\ and Akira FUJISHIMA
}

Received March 3, 1993 ; Accepted April 13, 1993

\begin{abstract}
1 INTRODUCTION
Optical second harmonic generation (SHG) at an interface affords the structural information when one analyzes the polarization and the phase angle of the signal SH waves $^{1,2)}$. We employed SHG coherent interferometry in order to study the molecular alignment in LangmuirBlodgett (LB) films of hemicyanine derivatives $^{3)}$ and demonstrated that the SHG fringe pattern observed for the LB sample, which was asymmetrically prepared on a glass substrate possessing monolayers of $Z$-type (i.e. hydrophobic chain towards the air) and X-type (i.e. hydrophilic site towards the air) on the opposite faces ( $X / Z$ type), appeared totally inverted from that of the symmetrically fabricated $L B$ sample ( $Z / Z$ type). In this communication, the same method was applied to the LB films of rhodamine $B$ derivatives having one or two alkyl chains $\left(\mathrm{C}_{18}\right)$ instead of the N-ethyl group ${ }^{4)}$.
\end{abstract}

\section{EXPERIMENTAL}

Mono- (RhB-1) or di-substituted (RhB-2)

Department of Synthetic Chemistry, Faculty of Engineering, University of Tokyo (Hongo 7-3-1, Bunkyo-ku, Tokyo 113, Japan) Key words: Optical Second Harmonic Generation, Polarization Interferometry, LB Films, Rhodamine $B$ Derivatives
Rhodamine B (Nihon Kanko Shikiso) (Fig. 1, 2) was mixed with arachidic acid and methyl arachidate by the molar ratio of 1:9:1 in a chloroform solution ${ }^{4}$. An LB film of the dye mixture was transferred onto the $0.8 \mathrm{~mm}$ thick fused quartz plate in a conventional manner; $18{ }^{\circ} \mathrm{C}$ pure water subphase, the surface pressure and the lifting speed were $40 \mathrm{dyn} / \mathrm{cm}$ and 5 $\mathrm{mm} / \mathrm{min}$, respectively. An $\mathrm{X}$-type $\mathrm{LB}$ film was made with an underlying SHG inactive spacer of a stearic acid LB film. SHG fringe patterns were measured by tilting the sample slide against the pump incidence of a pulsed Nd:YAG laser (1064 nm, $10 \mathrm{~Hz}, 7 \mathrm{~ns}$, ca.5-50 $\mathrm{mJ} / \mathrm{cm}^{2}$ ). The experimetal details were described elsewhere ${ }^{3}$.

\section{RESULTS AND DISCUSSION}

In contrast to the results for the hemicyanine derivatives ${ }^{3)}$ the observed SHG fringes for the $Z / Z$ and the $X / Z$ types of $\mathrm{RhB}-1$ samples are not inverted from each other (Fig. 1). This result suggests that the SHG active chromophore is, on the average, almost parallel to the glass surface with its chromophore bending 5) against the alkyl chain. Figure 1 also suggests that the $\mathrm{X}$-type $\mathrm{LB}$ film of $\mathrm{RhB}-1$ is less ordered judging from less intense envelope of the fringe pattern for an $X / Z$ sample than that for a $Z / Z$ type. 
The ratio of the total $\mathrm{SH}$ intensities by the $p$ - and s-polarized excitation is known to be a function of the average molecular orientation of the chromophore ${ }^{(.7)}$ and the xanthene structure of RhB-2 in $Z / Z$ type LB film could be estimated ca. 30 deg tilted from the surface normal, while ca. $50 \mathrm{deg}$ for RhB-1. The SHG measurements did not show any difference between along and across the lifting direction of the film, that is, the distribution of the molecular alignment of the chromophore was random inside the sample film.

Surprisingly, the pump polarization dependence for a $Z / Z$ type sample having RhB-1 on one face and RhB-2 on the other face of a glass slide revealed that the fringe pattern pumped by the $p-$ polarized incidence was inverted from the one excited by the s-polarization and also inverted from the $Z / Z$ samples of a single component. Assuming that the hyperpolarizability of the dye samples lie along the long axis of the xanthene structure the present observation is quite puzzling. Some possible explanations are either that the SHG in the RhB-1 film of $\mathrm{Z}$ type, assuming the random distribution of the xanthene structure of RhB-1, is attributable mainly to the $\mathbf{S}_{\circ} \rightarrow \mathbf{S}_{2}$ transition dipole moment along the z' axis $^{6)}$ (Fig. 1) which causes a phase difference from the resonant $S H G\left(S_{0} \rightarrow S_{1}\right.$, directed along the $x^{\prime}$ axis) of RhB-2, or that the dimeric form of $\mathrm{RhB}-1$ contributes to the phenomenon.

\section{REFERENCES}

1) R. M. Corn, Anal. Chem., 63, 285A (1991).

2) G. L. Richmond, in Electroanal. Chem. (vol.17), ed. A. J. Bard, Marcel Dekker (1991).
3) O. Sato, R. Baba, K. Hashimoto and A. Fujishima, J. Electro anal. Chem., 306, 291 (1991); O. Sato, R. Baba, K. Hashimoto and A. Fujishima, J. Phys. Chem., 95, 9635 (1992).

4) Y. Yonezawa, M. Ohno, S. Suga, K. Wataya and H. Hada, J. Chem. Soc. Jpn., 116 (1987).

5) G. Decher, B. Tieke, Ch. Bosshard and P. Günter, J. Chem. Soc. Chem. Commun., 933 (1988); G. Decher, B. Tieke, Ch. Bosshard and P. Günter, Ferroelectrics, 91, 193 (1989).

6) T. F. Heinz, C. K. Chen, D. Ricard and Y. R. Shen, Phys. Rev. Lett., 48, 478 (1982).

7) K. Kajikawa, H. Takezoe and A. Fukuda, Jpn. J. Appl. Phys., 30, 1050 (1991).

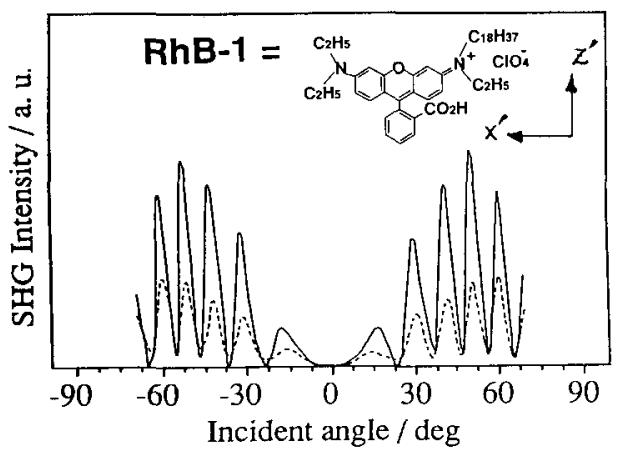

Fig. 1 SHG fringe pattern for $X / Z$ ( .............) and $Z / Z(-)$ types of LB film of $\mathrm{RhB}-1$ both pumped by the p-polarized light.

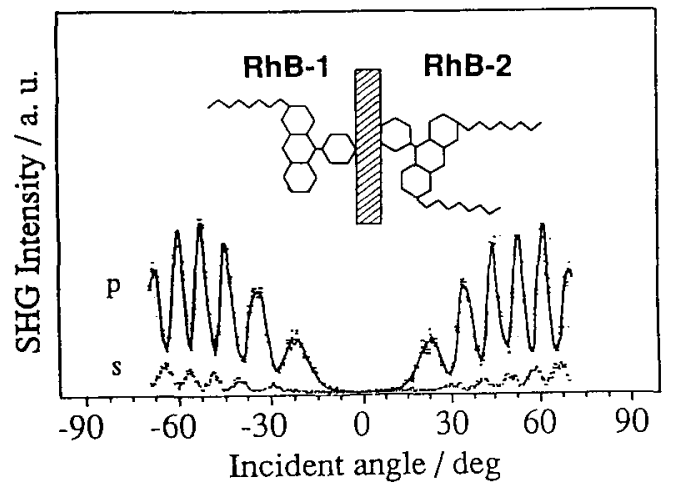

Fig. 2 Polarization dependence of the SHG fringe pattern for $Z-R h B-1 / Z-R h B-2$ sample. The pump beam was $\mathrm{p}-(-)$ or $\mathrm{s}-(\ldots . . . . . . . .$. polarized. 